\title{
The dimer, trimer and 1,2,4-trithiolane of adamantanethione
}

Linden, Anthony ; Fu, Changchun ; Majchrzak, Agnieszka ; Mlostoń, Grzegorz ; Heimgartner, Heinz

\begin{abstract}
The molecules of dispiro[1,3-dithietane-2,2':4,2"-diadamantane], C20H28S2, have crystallographic Ci symmetry, as well as local D2h symmetry, and a planar 1,3-dithietane ring. The molecules of trispiro[1,3,5-trithiane-2,2':4,2":6,2"'-triadamantane], C30H42S3, have approximate C2 symmetry and the 1,3,5- trithiane ring has a twist-boat conformation. The C-S-C bond angles within the ring are about $8^{\circ}$ larger than observed in most related 1,3,5-trithiane structures. In dispiro[1,2,4-trithiolane-3,2':5,2"diadamantane], $\mathrm{C} 20 \mathrm{H} 28 \mathrm{~S} 3$, the molecules have local $\mathrm{C} 2$ symmetry and the 1,2,4-trithiolane ring has a half-chair conformation.
\end{abstract}

DOI: https://doi.org/10.1107/S0108270102003190

Posted at the Zurich Open Repository and Archive, University of Zurich ZORA URL: https://doi.org/10.5167/uzh-81644

Journal Article

Published Version

Originally published at:

Linden, Anthony; Fu, Changchun; Majchrzak, Agnieszka; Mlostoń, Grzegorz; Heimgartner, Heinz (2002). The dimer, trimer and 1,2,4-trithiolane of adamantanethione. Acta Crystallographica. Section C: Crystal Structure Communications, 58(4):o231-o234.

DOI: https://doi.org/10.1107/S0108270102003190 
Acta Crystallographica Section C

Crystal Structure

Communications

ISSN 0108-2701

\section{The dimer, trimer and 1,2,4-trithiolane of adamantanethione}

\author{
Anthony Linden, ${ }^{a *}$ Changchun Fu, ${ }^{a}$ Agnieszka \\ Majchrzak, $^{\text {a,b }}$ Grzegorz Mloston ${ }^{b}$ and Heinz \\ Heimgartner $^{\mathrm{a}}$
}

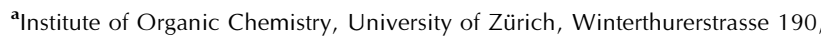
$\mathrm{CH}-8057$ Zürich, Switzerland, and ${ }^{\mathbf{b}}$ Section of Heteroorganic Compounds, University of Lodz, Narutowicza 68, PL-90-136 Lodz, Poland

Correspondence e-mail: alinden@oci.unizh.ch

Received 12 February 2002

Accepted 18 February 2002

Online 21 March 2002

The molecules of dispiro[1,3-dithietane-2,2':4,2'-diadamantane], $\mathrm{C}_{20} \mathrm{H}_{28} \mathrm{~S}_{2}$, have crystallographic $C_{i}$ symmetry, as well as local $D_{2 h}$ symmetry, and a planar 1,3-dithietane ring. The

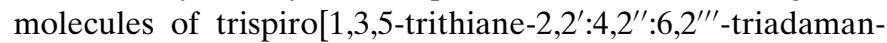
tane], $\mathrm{C}_{30} \mathrm{H}_{42} \mathrm{~S}_{3}$, have approximate $C_{2}$ symmetry and the $1,3,5-$ trithiane ring has a twist-boat conformation. The $\mathrm{C}-\mathrm{S}-\mathrm{C}$ bond angles within the ring are about $8^{\circ}$ larger than observed in most related 1,3,5-trithiane structures. In dispiro[1,2,4trithiolane-3,2':5,2'-diadamantane], $\mathrm{C}_{20} \mathrm{H}_{28} \mathrm{~S}_{3}$, the molecules have local $C_{2}$ symmetry and the 1,2,4-trithiolane ring has a half-chair conformation.

\section{Comment}

Interest in the chemistry of thiocarbonyl compounds has increased remarkably over the last few years. For example, thioketones have been used as 'superdipolarophiles' in 1,3dipolar cycloadditions (Fisera et al., 1996; Huisgen et al., 2001) and as 'superdienophiles' in hetero-Diels-Alder reactions (Schatz \& Sauer, 1994; Rohr et al., 1998). Thiocarbonyl compounds are also starting materials for the generation of thiocarbonyl ylides (Mloston \& Heimgartner, 2000) that are then used to prepare thia-heterocycles by 1,3-dipolar cycloadditions or by 1,3- as well as 1,5-dipolar electrocyclizations. In addition, thioketones and some other $\mathrm{C}=\mathrm{S}$-containing compounds have been shown to undergo Lewis acid-catalyzed reactions with oxiranes to yield 1,3-oxathiolanes (Blagoev et al., 2000; Fu et al., 2001).

In most of these studies, non-enolizable thioketones have been used as model compounds; for example, thiobenzophenone (Pedersen et al., 1978), 1,1,3,3-tetramethylindane-2thione (Klages \& Voss, 1980; Langhals \& Langhals, 1990), 2,2,4,4-tetramethyl-3-thioxocyclobutanone (Elam \& Davis, 1967) and adamantanethione (Greidanus, 1970). These thioketones proved to be relatively stable and they can be prepared conveniently by thionation of the corresponding ketones either by treatment with thionating reagents, such as
$\mathrm{P}_{4} \mathrm{~S}_{10}$ and Lawesson's reagent, or with a mixture of $\mathrm{H}_{2} \mathrm{~S}$ and $\mathrm{HCl}$. Several papers report the formation of dimers, trimers and other side products during the synthesis of thioketones (cf. Campaigne, 1946; Schönberg, 1955; Mayer et al., 1964; Bleisch \& Mayer, 1967; Scheibye et al., 1982; Sachweh \& Langhals, 1990). The first preparation of pure adamantanethione, (I), with $\mathrm{P}_{4} \mathrm{~S}_{10}$ in pyridine, was described by Greidanus (1970). He also observed that (I) undergoes dimerization and trimerization to give compounds (II) and (III) when treated with methanesulfonic acid (cf. Ishii et al., 1997). The dimer, (II), was also formed in high yields in reactions of (I) with $\alpha, \beta$ unsaturated carbonyl compounds, which act as heterodienes (Katada et al., 1984a), as well as with derivatives of 2-hydroxybenzyl alcohol and with hydrazonoyl chlorides (Katada et al., 1984b).

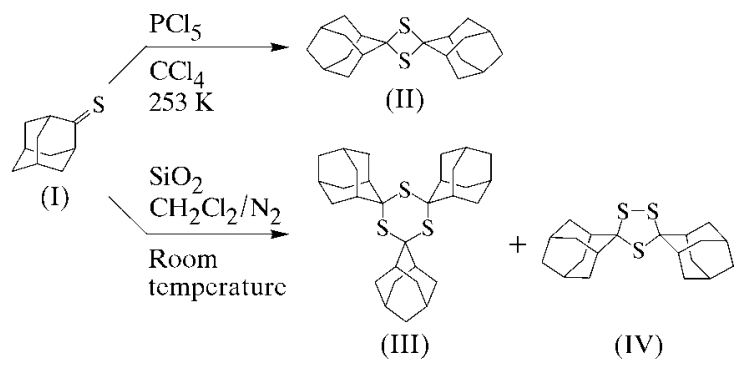

As part of our ongoing studies of the synthesis and reactivity of $\alpha$-chlorosulfenyl chlorides (Koch et al., 1999; Mloston, Majchrzak et al., 2002), we also tried to prepare 2-chloroadamantyl-2-sulfenyl chloride by treatment of (I) with phosphorus pentachloride in tetrachloromethane at $353 \mathrm{~K}$. Surprisingly, the 1,3-dithietane dimer, (II), was formed as the major product.

Treatment of (I) with silica gel in dichloromethane at room temperature resulted in a mixture of the trithiane trimer, (III), the 1,2,4-trithiolane, (IV), and unreacted (I) in the ratio 9:25:62, respectively. The trimer was successfully crystallized for the first time ( $c f$. Greidanus, 1970) from dichloromethane/ hexane. The main product, (IV), is a well known compound previously obtained as a side product in several reactions, such as the reaction of (I) with nitrile sulfides or sulfur (Wai \& Sammes, 1991), with sodium thiophenolate (Huisgen \& Rapp, 1997), with phosphorous pentasulfide (Okuma, Shibata et al., 2000) or with elemental sulfur (Okuma, Kojima et al., 2000). In each case, the sulfur-containing reagent can be envisaged as

Figure 1

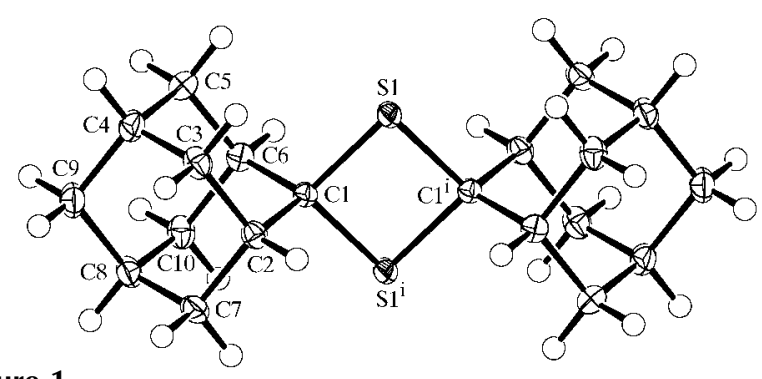

View of the molecule of (II) showing the atom-labelling scheme Displacement ellipsoids are drawn at the $50 \%$ probability level. [Symmetry code: (i) $2-x,-y,-z$.] 
being the source of the additional $S$ atom. However, compound (IV) has also been obtained when (I) was the only sulfur compound present in the reaction mixture, such as in reactions of (I) with organic azides (Mloston, Romanski \& Heimgartner, 1996; Mloston, Romanski, Linden et al., 1996) and with tributylammonium fluoride (Mloston, Prakash et al., 2002). A reaction mechanism for the formation of 1,2,4-trithiolanes from thioketones and organic azides has been proposed (Mloston \& Heimgartner, 1995; Mloston, Romanski et al., 1995). As part of their full characterization, lowtemperature X-ray crystal structure determinations of compounds (II), (III) and (IV) were carried out.

The molecule of compound (II) sits across a crystallographic centre of inversion and, as a consequence, the 1,3dithietane ring is planar (Fig. 1). In addition, the molecule has local $D_{2 h}$ symmetry, with an r.m.s. fit of $0.015 \AA$. The $\mathrm{C}-\mathrm{S}-\mathrm{C}$ bond angles are significantly less than $90^{\circ}$, while the $\mathrm{S}-\mathrm{C}-\mathrm{S}$ angles are correspondingly larger than $90^{\circ}$ (Table 1). The literature reports only five other structures that have a 1,3dithietane ring with unsubstituted-S and $s p^{3} \mathrm{C}$ atoms. The structure of 1,1,3,3-tetrachloro-2,4-dithiacyclobutane (Krebs \& Beyer, 1969; Boese et al., 1993) is the only one where the molecule has crystallographic $C_{i}$ symmetry, although the molecule of trans-2,4-dimethyl-2,4-bis(thioacetylthio)-1,3dithietane (Mikołajczyk et al., 1977) has pseudo- $C_{i}$ symmetry and a planar 1,3-dithietane ring. In both anti-bis(camphor)1,3-dithietane (Back et al., 1995) and 2,4-bis(cymantrenyl)-2,4dimethyl-1,3-dithietane (Batsanov et al., 1992), the molecules have local $C_{2}$ symmetry about an axis perpendicular to the plane of the 1,3-dithietane ring. In the former compound, the 1,3-dithietane ring is almost planar, being folded about the S $\cdots$ S and C $\cdots$ C axes by approximately $4^{\circ}$, while in the latter compound, the ring is folded more significantly, the fold being approximately $12^{\circ}$ about both the S $\cdots \mathrm{S}$ and $\mathrm{C} \cdots \mathrm{C}$ axes. In 1,4-diphenyl-2,2,3,3-tetramethyl-5,6-dithiabicyclo[2.1.1]hexane (Block et al., 1997), the two dithietane ring $\mathrm{C}$ atoms are

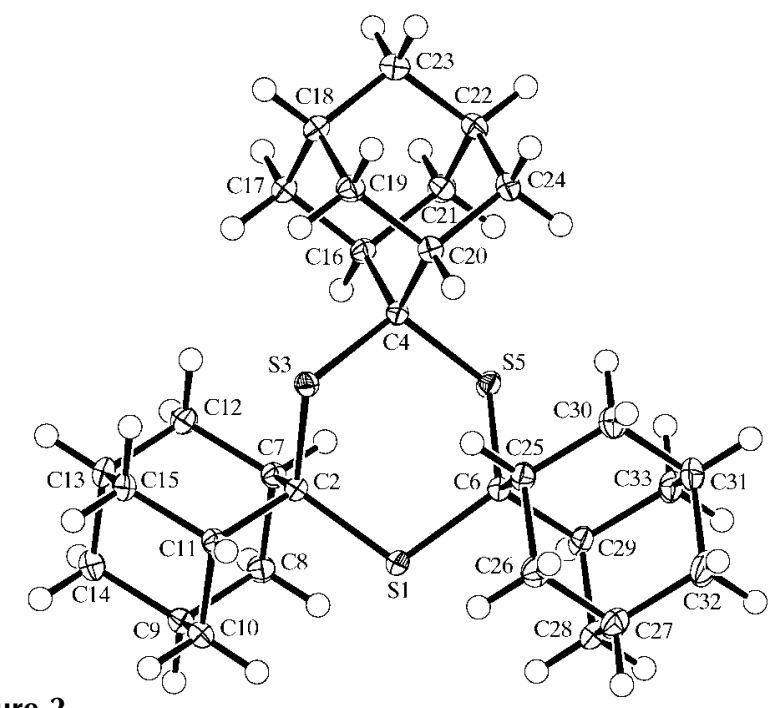

Figure 2

View of the molecule of (III) showing the atom-labelling scheme. Displacement ellipsoids are drawn at the $50 \%$ probability level. bridged by an ethylene group, which constrains the $\mathrm{C}-\mathrm{S}-\mathrm{C}$ bonds to be part of a five-membered ring. This produces severe folding of the 1,3-dithietane ring into a $\mathrm{V}$-shape about both the S $\cdots \mathrm{S}$ and $\mathrm{C} \cdots \mathrm{C}$ axes, the folds being 61.7 and $52.8^{\circ}$, respectively. The $\mathrm{C}-\mathrm{S}$ bond lengths and $\mathrm{C}-\mathrm{S}-\mathrm{C}$ and $\mathrm{S}-\mathrm{C}-$ $\mathrm{S}$ angles in the 1,3-dithietane ring of (II) are similar to those in all of the related compounds, with the exception of the highly puckered ring of 1,4-diphenyl-2,2,3,3-tetramethyl-5,6-dithiabicyclo[2.1.1] hexane, where the ring strain reduces the $\mathrm{C}-\mathrm{S}-$ $\mathrm{C}$ angles to a mean value of $73.4(1)^{\circ}$.

The molecule of compound (III) has approximate $C_{2}$ symmetry about an axis passing through $\mathrm{S} 1$ and $\mathrm{C} 4$, with an r.m.s. fit of $0.17 \AA$ (Fig. 2). The 1,3,5-trithiane ring has an almost perfect twist-boat conformation, with puckering parameters (Cremer \& Pople, 1975) $Q=0.990$ (1) ̊, $q_{2}=$ 0.990 (1) $\AA, q_{3}=0.003$ (1) $\AA, \varphi_{2}=90.26(6)^{\circ}$ and $\theta=89.8(1)^{\circ}$ for the atom sequence $\mathrm{S} 1-\mathrm{C} 2-\mathrm{S} 3-\mathrm{C} 4-\mathrm{S} 5-\mathrm{C} 6$. The Cambridge Structural Database (CSD, October 2001 release; Allen \& Kennard, 1993) contains 19 entries covering 12 compounds that have a 1,3,5-trithiane ring with unsubstituted$\mathrm{S}$ and $s p^{3} \mathrm{C}$ atoms, excluding those where the ring is part of a hexathiaadamantane moiety. Of these, the only structure in which the 1,3,5-trithiane ring has a twist-boat conformation is that of trans-2,4,6-tris(trichloromethyl)-1,3,5-trithiane (Irving \& Irving, 1987), while a chair conformation is found in all of the remaining structures. The overall mean $\mathrm{C}-\mathrm{S}$ bond length and $\mathrm{C}-\mathrm{S}-\mathrm{C}$ and $\mathrm{S}-\mathrm{C}-\mathrm{S}$ angles in the 1,3,5-trithiane ring of these 19 literature structures are 1.818 (6) $\AA, 100.3(8)^{\circ}$ and $113.7(5)^{\circ}$, respectively. The $\mathrm{C}-\mathrm{S}$ bond lengths of (III) have a mean value of 1.837 (2) $\AA$ and are similar to the mean value for the other structures, although the S1-C2 and S1-C6 bonds are slightly longer (Table 2). More significant are the $\mathrm{C}-\mathrm{S}-\mathrm{C}$ angles of (III), whose mean value of $108.73(9)^{\circ}$ is over $8^{\circ}$ larger than the overall mean value for the other structures, while the $\mathrm{S}-\mathrm{C}-\mathrm{S}$ angles for (III) have a mean value of $110.8(1)^{\circ}$, which is about $3^{\circ}$ smaller than the mean value for the other structures. This variation in the angles within the 1,3,5-trithiane ring might be a result of each $\mathrm{C}$ atom of the ring being disubstituted. The only other reported 1,3,5trithiane structure with disubstituted ring $\mathrm{C}$ atoms is that of $\beta$-2,4,6-triphenyl-2,4,6-tris(trimethylsilyl)-1,3,5-trithiane (Bonini et al., 1988), and this structure also has enlarged $\mathrm{C}-\mathrm{S}-\mathrm{C}$ and contracted $\mathrm{S}-\mathrm{C}-\mathrm{S}$ angles similar to those observed for compound (III).

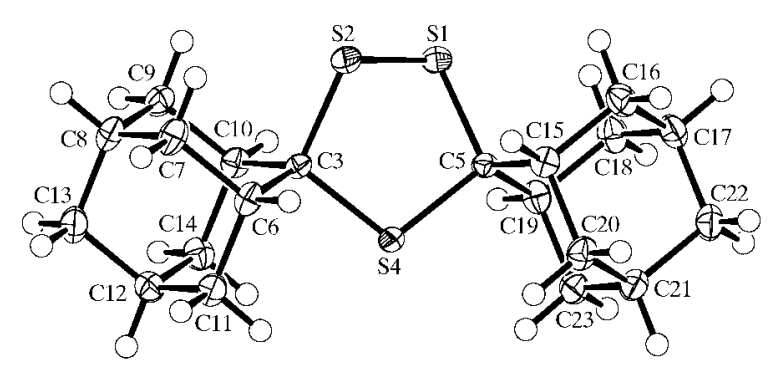

Figure 3

View of the molecule of (IV) showing the atom-labelling scheme. Displacement ellipsoids are drawn at the $50 \%$ probability level. 
The molecule of compound (IV) has local $C_{2}$ symmetry about an axis passing through $\mathrm{S} 4$ and the midpoint of the $\mathrm{S} 1-$ S2 bond, with an r.m.s. deviation of $0.028 \AA$ (Fig. 3). The 1,2,4trithiolane ring has a half-chair conformation twisted on the S1 $1-\mathrm{S} 2$ bond, with puckering parameters $q_{2}=0.692$ (1) $\AA$ and $\varphi_{2}=15.95(8)^{\circ}$ for the atom sequence S1-S2-C3-S4-C5. Atoms S1 and S2 deviate from the plane defined by atoms C3, S4 and C5 by 0.630 (1) and -0.512 (1) $\AA$, respectively. The CSD contains 17 entries for reported structures that have a 1,2,4-trithiolane ring with unsubstituted-S and $s p^{3} \mathrm{C}$ atoms, but geometrical data are available for only eight of these. The bond lengths and angles within the 1,2,4-trithiolane ring of compound (IV) (Table 3) are consistent with those of these related structures. There does not seem to be a preference for the conformation of the 1,2,4-trithiolane ring, as an envelope conformation or a distorted variant thereof is found in four of the eight related structures for which data are available.

\section{Experimental}

For the preparation of (II), phosphorus pentachloride (765 mg, $3.6 \mathrm{mmol}$ ) was added to a solution of adamantanethione, (I) (300 mg, $1.8 \mathrm{mmol})$, in tetrachloromethane $(10 \mathrm{ml})$ and the mixture was heated under reflux $(353 \mathrm{~K})$ for $7 \mathrm{~h}$. The mixture was then poured onto ice, the organic phase was extracted with aqueous $\mathrm{NaHCO}_{3}$ solution $(\times 3)$ and water $(\times 3)$, dried over $\mathrm{MgSO}_{4}$, filtered, and the solvent evaporated. The crude residue $(256 \mathrm{mg})$ was recrystallized from hexane/dichloromethane, yielding $169 \mathrm{mg}(56.3 \%)$ of (II) as colourless prisms (m.p. 578-580 K). Single crystals of (II) were obtained by slow evaporation of a solution in hexane/dichloromethane.

For the preparation of (III) and (IV), silica gel ( $4.0 \mathrm{~g})$ was added to a solution of (I) $(66 \mathrm{mg}, 0.4 \mathrm{mmol})$ in dry dichloromethane $(10 \mathrm{ml})$ under a nitrogen atmosphere at room temperature. After stirring the mixture for $3 \mathrm{~d}$ at room temperature, the suspension was filtered, the residue was washed with dichloromethane $(\times 4)$, and the filtrate was evaporated. Chromatographic separation $\left(\mathrm{SiO}_{2}\right.$, hexane $\left./ \mathrm{CH}_{2} \mathrm{Cl}_{2} 10: 1\right)$ and crystallization gave $6 \mathrm{mg}$ (9\%) of (III) as colourless needles [m.p. 618.9-619.4 K (decomposition)] and $12 \mathrm{mg}(25 \%)$ of (IV) as colourless prisms (m.p. 468.4-469.7 K). In addition, $41 \mathrm{mg}$ (62\%) of (I) were recovered. Single crystals of (III) and (IV) were obtained by slow evaporation of solutions in dichloromethane/hexane and chloroform/ dichloromethane/methanol, respectively.

\section{Compound (II)}

\section{Crystal data}

$\mathrm{C}_{20} \mathrm{H}_{28} \mathrm{~S}_{2}$

$M_{r}=332.56$

Monoclinic, $P 2_{1} / n$

$a=6.4567(1) \AA$

$b=12.0271(2) \AA$

$c=10.7163(2) \AA$

$\beta=93.8719(5)^{\circ}$

$V=830.28(2) \AA^{3}$

$Z=2$

$$
\begin{aligned}
& D_{x}=1.330 \mathrm{Mg} \mathrm{m}^{-3} \\
& \text { Mo } K \alpha \text { radiation } \\
& \text { Cell parameters from } 17358 \\
& \quad \text { reflections } \\
& \theta=2.0-30.0^{\circ} \\
& \mu=0.32 \mathrm{~mm}^{-1} \\
& T=160(1) \mathrm{K} \\
& \text { Prism, colourless } \\
& 0.25 \times 0.25 \times 0.20 \mathrm{~mm}
\end{aligned}
$$

Table 1

Selected geometric parameters $\left(\AA{ }^{\circ}{ }^{\circ}\right)$ for (II).

\begin{tabular}{llll}
\hline $\mathrm{S} 1-\mathrm{C} 1$ & $1.8411(10)$ & $\mathrm{S} 1-\mathrm{Cl}^{\mathrm{i}}$ & $1.8432(10)$ \\
$\mathrm{C} 1-\mathrm{S} 1-\mathrm{Cl}^{\mathrm{i}}$ & $85.76(4)$ & $\mathrm{S} 1-\mathrm{C} 1-\mathrm{S} 1^{\mathrm{i}}$ & $94.24(4)$ \\
\hline
\end{tabular}

Symmetry code: (i) $2-x,-y,-z$.

\section{Data collection}

Nonius KappaCCD diffractometer $\varphi$ and $\omega$ scans with $\kappa$ offsets

Absorption correction: multi-scan

(SORTAV; Blessing, 1995)

$T_{\min }=0.769, T_{\max }=0.830$

29949 measured reflections

2410 independent reflections

\section{Refinement}

Refinement on $F^{2}$

$R\left[F^{2}>2 \sigma\left(F^{2}\right)\right]=0.031$

$w R\left(F^{2}\right)=0.081$

$S=1.09$

2409 reflections

100 parameters

$\mathrm{H}$-atom parameters constrained

\section{Compound (III)}

$$
\begin{aligned}
& \text { Crystal data } \\
& \mathrm{C}_{30} \mathrm{H}_{42} \mathrm{~S}_{3} \\
& M_{r}=498.84 \\
& \text { Triclinic, } P \overline{1} \\
& a=6.6436(1) \AA \\
& b=12.3102(2) \AA \\
& c=15.6057(2) \AA \\
& \alpha=77.0671(5)^{\circ} \\
& \beta=86.7263(6)^{\circ} \\
& \gamma=77.1671(7)^{\circ} \\
& V=1212.81(3) \AA^{3}
\end{aligned}
$$

\section{Data collection}

Nonius KappaCCD diffractometer $\varphi$ and $\omega$ scans with $\kappa$ offsets

Absorption correction: multi-scan

(SORTAV; Blessing, 1995)

$T_{\min }=0.914, T_{\max }=0.970$

50920 measured reflections

7114 independent reflections

\section{Refinement}

Refinement on $F^{2}$

$R\left[F^{2}>2 \sigma\left(F^{2}\right)\right]=0.035$

$w R\left(F^{2}\right)=0.094$

$S=1.05$

7113 reflections

298 parameters

$\mathrm{H}$-atom parameters constrained

\author{
$Z=2$ \\ $D_{x}=1.366 \mathrm{Mg} \mathrm{m}^{-3}$ \\ Mo $K \alpha$ radiation \\ Cell parameters from 47672 \\ reflections \\ $\theta=2.0-30.0^{\circ}$ \\ $\mu=0.32 \mathrm{~mm}^{-1}$ \\ $T=160$ (1) K \\ Needle, colourless \\ $0.25 \times 0.12 \times 0.10 \mathrm{~mm}$
}

Table 2

Selected geometric parameters $\left(\AA{ }^{\circ}\right)$ for (III).

\begin{tabular}{llll}
\hline S1-C2 & $1.8501(12)$ & S3-C4 & $1.8341(12)$ \\
S1-C6 & $1.8511(12)$ & S5-C6 & $1.8270(13)$ \\
S3-C2 & $1.8245(12)$ & S5-C4 & $1.8370(12)$ \\
& & & \\
C2-S1-C6 & $108.59(5)$ & S3-C2-S1 & $110.51(6)$ \\
C2-S3-C4 & $108.70(5)$ & S3-C4-S5 & $111.26(6)$ \\
C6-S5-C4 & $108.91(5)$ & S5-C6-S1 & $110.52(6)$ \\
\hline
\end{tabular}

\section{Compound (IV)}

$\begin{array}{ll}\text { Crystal data } & \\ \mathrm{C}_{20} \mathrm{H}_{28} \mathrm{~S}_{3} & D_{x}=1.359 \mathrm{Mg} \mathrm{m}^{-3} \\ M_{r}=364.62 & \text { Mo } K \alpha \text { radiation } \\ \text { Monoclinic, } P 2_{1} / c & \text { Cell parameters from } 5453 \\ a=13.3264(2) \AA & \text { reflections } \\ b=11.5166(1) \AA & \theta=2.0-30.0^{\circ} \\ c=12.9233(1) \AA & \mu=0.41 \mathrm{~mm}^{-1} \\ \beta=116.0645(5)^{\circ} & T=160(1) \mathrm{K} \\ V=1781.69(3) \AA^{3} & \text { Prism, colourless } \\ Z=4 & 0.20 \times 0.15 \times 0.10 \mathrm{~mm}\end{array}$

5854 reflections with $I>2 \sigma(I)$

$R_{\text {int }}=0.053$

$\theta_{\text {max }}=30.0^{\circ}$

$h=-9 \rightarrow 9$

$k=-17 \rightarrow 17$

$l=-21 \rightarrow 21$ 


\section{Data collection}

Nonius KappaCCD diffractometer $\varphi$ and $\omega$ scans with $\kappa$ offsets 50637 measured reflections 5220 independent reflections 4190 reflections with $I>2 \sigma(I)$

$$
\begin{aligned}
& R_{\text {int }}=0.044 \\
& \theta_{\max }=30.1^{\circ} \\
& h=-18 \rightarrow 16 \\
& k=-16 \rightarrow 0 \\
& l=0 \rightarrow 18
\end{aligned}
$$

\section{Refinement}

Refinement on $F^{2}$

$R\left[F^{2}>2 \sigma\left(F^{2}\right)\right]=0.036$

$w R\left(F^{2}\right)=0.097$

$S=1.04$

5217 reflections

208 parameters

$\mathrm{H}$-atom parameters constrained

$$
\begin{gathered}
w=1 /\left[\sigma^{2}\left(F_{o}{ }^{2}\right)+(0.0467 P)^{2}\right. \\
+0.6782 P] \\
\text { where } P=\left(F_{o}{ }^{2}+2 F_{c}{ }^{2}\right) / 3 \\
(\Delta / \sigma)_{\max }=0.001 \\
\Delta \rho_{\max }=0.36 \mathrm{e} \AA^{-3} \\
\Delta \rho_{\min }=-0.36 \mathrm{e}^{-3}
\end{gathered}
$$

Table 3

Selected geometric parameters $\left(\AA,^{\circ}\right)$ for (IV).

\begin{tabular}{lcll}
\hline $\mathrm{S} 1-\mathrm{C} 5$ & $1.8334(12)$ & $\mathrm{S} 4-\mathrm{C} 3$ & $1.8532(12)$ \\
$\mathrm{S} 1-\mathrm{S} 2$ & $2.0281(5)$ & $\mathrm{S} 4-\mathrm{C} 5$ & $1.8554(12)$ \\
$\mathrm{S} 2-\mathrm{C} 3$ & $1.8378(12)$ & & \\
$\mathrm{C} 5-\mathrm{S} 1-\mathrm{S} 2$ & $96.13(4)$ & $\mathrm{S} 2-\mathrm{C} 3-\mathrm{S} 4$ & $106.08(6)$ \\
$\mathrm{C} 3-\mathrm{S} 2-\mathrm{S} 1$ & $96.22(4)$ & $\mathrm{S} 1-\mathrm{C} 5-\mathrm{S} 4$ & $105.40(6)$ \\
$\mathrm{C} 3-\mathrm{S} 4-\mathrm{C} 5$ & $104.53(5)$ & & \\
\hline
\end{tabular}

For each structure, all $\mathrm{H}$ atoms were placed in geometrically idealized positions $(\mathrm{C}-\mathrm{H}=0.99-1.00 \AA)$ and constrained to ride on their parent atoms, with $U_{\text {iso }}(\mathrm{H})=1.2 U_{\text {eq }}(\mathrm{C})$.

For all compounds, data collection: COLLECT (Nonius, 2000); cell refinement: $D E N Z O-S M N$ (Otwinowski \& Minor, 1997); data reduction: DENZO-SMN and SCALEPACK (Otwinowski \& Minor, 1997); program(s) used to solve structure: SIR92 (Altomare et al., 1994); $\operatorname{program}(\mathrm{s})$ used to refine structure: SHELXL97 (Sheldrick, 1997); molecular graphics: ORTEPII (Johnson, 1976); software used to prepare material for publication: SHELXL97 and PLATON (Spek, 2002).

Financial support from the Swiss National Science Foundation, F. Hoffmann-La Roche AG, Basel, and the Polish State Committee for Scientific Research (grant No. 3-T09A 007 16) is gratefully acknowledged.

Supplementary data for this paper are available from the IUCr electronic archives (Reference: TR1020). Services for accessing these data are described at the back of the journal.

\section{References}

Allen, F. H. \& Kennard, O. (1993). Chem. Des. Autom. News, 8, 1, 31-37. Altomare, A., Cascarano, G., Giacovazzo, C., Guagliardi, A., Burla, M. C., Polidori, G. \& Camalli, M. (1994). J. Appl. Cryst. 27, 435.

Back, T. G., Dyck, B. P. \& Parvez, M. (1995). J. Org. Chem. 60, 703-710.

Batsanov, A. S., Struchkov, Yu. T., Dolgova, S. P., Setkina, V. N., Galakhov, M. A., Yakushin, S. V. \& Nekrasov, Yu. S. (1992). Metalloorg. Khim. 5, $985-$ 992.

Blagoev, M., Linden, A. \& Heimgartner, H. (2000). Helv. Chim. Acta, 83, 3163-3178.

Bleisch, S. \& Mayer, R. (1967). Chem. Ber. 100, 93-100.
Blessing, R. H. (1995). Acta Cryst. A51, 33-38.

Block, E., Glass, R. S., DeOrazio, R., Lichtenberger, D. L., Pollard, J. R., Russell, E. E., Schroeder, T. B., Thiruvazhi, M. \& Toscano, P. J. (1997). Synlett, pp. 525-528.

Boese, R., Bläser, D. \& Stellberg, P. (1993). Z. Kristallogr. 206, 308-309.

Bonini, B. F., Mazzanti, G., Zani, P., Maccagnani, G. \& Foresti, E. (1988). J. Chem. Soc. Perkin Trans. 1, pp. 1499-1502.

Campaigne, E. (1946). Chem. Rev. 39, 1-77.

Cremer, D. \& Pople, J. A. (1975). J. Am. Chem. Soc. 97, 1354-1358.

Elam, E. U. \& Davis, H. E. (1967). J. Org. Chem. 32, 1562-1565.

Fisera, L., Huisgen, R., Kalwinsch, I., Langhals, E., Li, X., Mloston, G., Polborn, K., Rapp, J., Sicking, W. \& Sustmann, R. (1996). Pure Appl. Chem. 68, 789-798.

Fu, C., Linden, A. \& Heimgartner, H. (2001). Helv. Chim. Acta, 84, 3319-3334. Greidanus, J. W. (1970). Can. J. Chem. 48, 3530-3536.

Huisgen, R., Li, X., Giera, H. \& Langhals, E. (2001). Helv. Chim. Acta, 84, $981-$ 999.

Huisgen, R. \& Rapp, J. (1997). Heterocycles, 45, 507-525.

Irving, A. \& Irving, H. M. N. H. (1987). J. Crystallogr. Spectrosc. Res. 17, $295-$ 301.

Ishii, A., Akazawa, T., Ding, M.-X., Honjo, T., Maruta, T., Nakamura, S., Nagaya, H., Ogura, M., Teramoto, K., Shiro, M., Hoshino, M. \& Nakayama, J. (1997). Bull. Chem. Soc. Jpn, 70, 507-523.

Johnson, C. K. (1976). ORTEPII. Report ORNL-5138. Oak Ridge National Laboratory, Tennessee, USA.

Katada, T., Eguchi, S., Esaki, T. \& Sasaki, T. (1984a). J. Chem. Soc. Perkin Trans. 1, pp. 1869-1874.

Katada, T., Eguchi, S., Esaki, T. \& Sasaki, T. (1984b). J. Chem. Soc. Perkin Trans. 1, pp. 2649-2653.

Klages, C. P. \& Voss, J. (1980). Chem. Ber. 133, 2255-2277.

Koch, K. N., Mloston, G. \& Senning, A. (1999). Eur. J. Org. Chem. pp. 83-86.

Krebs, B. \& Beyer, H. (1969). Z. Anorg. Allg. Chem. 365, 199-210.

Langhals, E. \& Langhals, H. (1990). Tetrahedron Lett. 31, 859-862.

Mayer, R., Morgenstern, J. \& Fabian, J. (1964). Angew. Chem. Int. Ed. Engl. 3, 277-287.

Mikołajczyk, M., Kiełbasinski, P., Barlow, J. H. \& Russell, D. R. (1977). J. Org. Chem. 42, 2345-2347.

Mloston, G. \& Heimgartner, H. (1995). Helv. Chim. Acta, 78, 1298-1310.

Mloston, G. \& Heimgartner, H. (2000). Pol. J. Chem. 74, 1503-1532.

Mloston, G., Majchrzak, A., Senning, A. \& Søtofte, I. (2002). Eur. J. Org. Chem. In the press.

Mloston, G., Prakash, G. K. S., Olah, G. A. \& Heimgartner, H. (2002). Helv. Chim. Acta. Submitted.

Mloston, G., Romanski, J. \& Heimgartner, H. (1996). Pol. J. Chem. 70, 437445.

Mloston, G., Romanski, J., Linden, A. \& Heimgartner, H. (1995). Helv. Chim. Acta, 78, 1499-1510.

Mloston, G., Romanski, J., Linden, A. \& Heimgartner, H. (1996). Pol. J. Chem. 70, 595-602.

Nonius (2000). COLLECT. Nonius BV, Delft, The Netherlands.

Okuma, K., Kojima, K. \& Shibata, S. (2000). Heterocycles, 53, 2753-2758.

Okuma, K., Shibata, S., Shioji, K. \& Yokomori, Y. (2000). Chem. Commun. pp. $1535-1536$.

Otwinowski, Z. \& Minor, W. (1997). Methods in Enzymology, Vol. 276, Macromolecular Crystallography, Part A, edited by C. W. Carter Jr \& R. M. Sweet, pp. 307-326. New York: Academic Press.

Pedersen, B. S., Scheibye, S., Nilsson, N. H. \& Lawesson, S.-O. (1978). Bull. Soc. Chim. Belg. 87, 223-228.

Rohr, U., Schatz, J. \& Sauer, J. (1998). Eur. J. Org. Chem. pp. 2875-2883.

Sachweh, V. \& Langhals, H. (1990). Chem. Ber. 123, 1981-1987.

Schatz, J. \& Sauer, J. (1994). Tetrahedron Lett. 35, 4767-4770.

Scheibye, S., Shabana, R. \& Lawesson, S.-O. (1982). Tetrahedron, 38, $993-$ 1001.

Schönberg, A. (1955). Methoden der Organischen Chemie (Houben-Weyl),

Vol. IX, edited by E. G. Müller, pp. 704-740. Stuttgart: Thieme Verlag.

Sheldrick, G. M. (1997). SHELXL97. University of Göttingen, Germany.

Spek, A. L. (2002). PLATON. University of Utrecht, The Netherlands.

Wai, K.-F. \& Sammes, M. P. (1991). J. Chem. Soc. Perkin Trans. 1, pp. 183-187. 